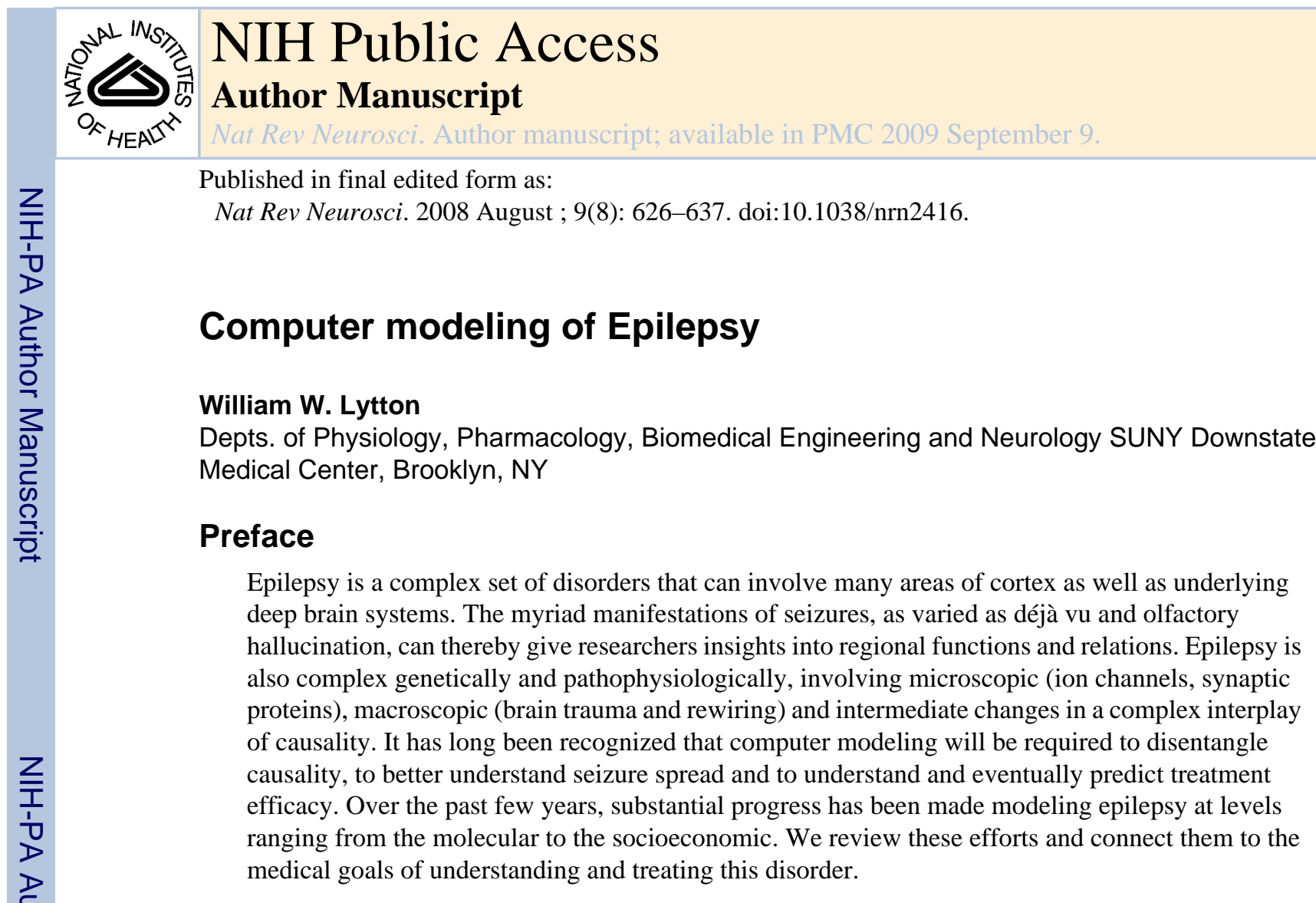

\begin{abstract}
Epilepsy is one of several paroxysmal or episodic disorders of the brain. These disorders, which include multiple sclerosis (MS), transient ischemic attacks (TIAs) and migraine are all dynamical diseases, diseases that unfold in time. ${ }^{59}$ While MS involves the dynamics of the immune system and TIA involves hemodynamics, epilepsy is a dynamical disorder of the brain itself. Epilepsy is therefore particularly suited to study from the perspective of computer modeling and dynamical systems theory.
\end{abstract}

Online summary

- Computer modeling of epilepsy is a branch of systems biology, the effort to combine the discoveries made by reductionist approaches into systems so as to understand how primary pathologies and secondary reactions interact to produce disease. Epilepsy, a dynamical disease of the brain, is well suited to study from the perspective of dynamical systems.

- Epilepsy is a complex set of disorders with the commonality of recurrent seizures. Not only do the many individual epilepsy syndromes have different causes, most epilepsies develop due to the interaction of many causes at molecular, cellular, network and developmental levels, defying efforts to define simple cause and effect relations and suggesting the need for computer modeling.

- Knowledge discovery and data-mining provides the substrate and support for dynamical modeling and allows model findings to be applied back to the research and clinical settings. The variety of dynamical modeling techniques used include stochastic models, low-dimensional (lumped) deterministic models and detailed neuronal network models.

- Computer models are applied across the range of epilepsy phenomenology from the molecular to the clinical. At the patient level, Markov models have been used to assess patterns of remission and relapse in pediatric epilepsy. At the molecular level, deterministic models can predict alterations in cellular activity with ion channel mutations.

- Many seizure models simulate activity at the network level. Some of these are lumped models which use mean-field approximations to reduce the activity of many neurons to simple oscillators which are then coupled to produce complex activity patterns. Other models incorporate the details of neural activity and synaptic interactions in order to reach down to the molecular level where drug effects take place.

- Uncommon among areas of neuroscience research, computer modeling is immediately accessible through downloads of established models. An intrinsically collaborative activity, the future of the endeavor lies in the cooperative efforts of clinicians, experimentalists and modelers. 
The signs and symptoms of epilepsy are varied, likely due to the fact that epilepsy can involve many areas of cortex as well as underlying deep brain systems. Epilepsy is therefore a fascinating disease for both the clinician and for those interested in the functioning of brain subsystems and their dynamic interrelations.

Progress in understanding epilepsy has been made in all areas of neuroscience, from neurogenetics and protein crystallography through imaging and behavior. Modeling can be used to tie together these subfields and understand one level of organization in terms of others. 130 The concordance between basic science and clinical phenomenology is closer in epilepsy than in most brain disorders. Computer simulation can conceptually link abnormalities at different levels of organization that are identified by experiment.

This review will focus on two major epilepsy syndromes that are particularly well studied in modeling and experimental preparations: childhood absence epilepsy and medial temporal lobe epilepsy (MTLE). Absence seizures are brief episodes of loss of consciousness without convulsions. Absence is considered a primary generalized seizure, although recent findings suggest that an individual absence seizure does have a focal onset. ${ }^{102}$ Experimentation and modeling strongly implicate thalamocortical interactions in this disorder. ${ }^{17,} 33,88$

By contrast, MTLE produces alterations in consciousness and convulsions. The seizures spread from temporal lobe in a process termed secondary generalization. MTLE is considered the prototypical focal epilepsy disorder ${ }^{25}$ and MTLE is thought to be largely acquired, presumably by injury and the brain's subsequent reaction to injury. ${ }^{128}$ However, familial factors are also important. $^{5}$, 46, 74, 94, 116, 129

This review will describe several levels and types of models to give the flavor of modeling, and to highlight recent progress and the potential for therapeutic application. I proceed from the macroscopic to the microscopic level, and from modeling the dynamics of seizure occurrence in the pediatric population to a detailed model that takes into account the dynamics of voltage-sensitive ion channels. Throughout, I compare conceptual and dynamical models and indicate how the conceptual model is used as a foundation for a dynamical interpretation of the data. This broad scope has required the omission of many major works in the field in favor of a few studies that illustrate particular approaches. Readers whose curiosity is piqued are referred to Ref. 133.

\section{What is epilepsy?}

An initial understanding (or model) of something is generally provided by a textbook or dictionary definition, which can provide a root and route to broader taxonomic and classification schemes. The common feature of the epilepsies is the occurrence and recurrence of seizures: thus, epilepsy is a seizure disorder. A seizure is a "transient occurrence of signs and/or symptoms due to abnormal excessive or synchronous neuronal activity in the brain." ${ }^{48}$ An additional aspect of the clinical definition is the involvement of cerebral cortex, allowing seizures to be distinguished from excessive or synchronous activity elsewhere in the brain: e.g., a tremor or the pain arising from a brainstem ganglion (trigeminal neuralgia). In the research literature, the term seizure is applied to excessive neurological activity in creatures as petite and acortical as zebra fish and fruit flies. ${ }^{3}, 133$ This is reasonable, as the animal syndromes involved do respond to anticonvulsants (as does trigeminal neuralgia) and thus enable investigators to assess drugs and genetic manipulations that would be impossible in larger animals.

Difficulty in defining epilepsy arises in part from the vast diversity of epilepsy syndromes and seizure manifestations. The current standard clinical classification can be confusing due to its occasional conflation of etiology and manifestation. ${ }^{40}$ Efforts to amend and replace this 
classification scheme have led to disagreements and competing suggestions for standards. ${ }^{41}$, $42,48,49,71,109,156$ Nevertheless, the competing classifications all agree on the use of multidimensional axes to organize our thinking about the disease (Box 1). Ideally these schemes will provide a basis for formal (computerized) epilepsy ontologies in the future. ${ }^{29}$, 163

The difficulty in epilepsy definition also reflects the perennial clinical conflict between splitters and lumpers. ${ }^{49,}{ }^{109}$ Splitters want to divide epilepsy into distinct conditions, whereas lumpers suggest that manifestations and causes overlap so greatly that there is little value in splitting. Both views have validity. Several distinct epilepsy syndromes, such as childhood absence and MTLE, can be identified. However, epilepsy generally arises from a confluence of polygenic, proteomic and acquired causes (Fig. 1). ${ }^{56}$ A particular genomic/proteomic makeup provides an interacting substrate of ion channels, synaptic weights and network configurations that make an individual more or less prone to develop epilepsy in response to stroke, head trauma or simple lack of sleep. ${ }^{8,9}, 107,135$ Conversely, a particular ion channel mutation, even one that is invariably epileptogenic, will produce different disease manifestations in two individuals due to differences in other channels, network anatomy, and acquired brain insults.

The complexity of multifactorial causation highlights the need for a computational approach. While it is possible to experimentally determine and informally conceptualize how a single mutation could produce a seizure, it requires modeling to understand how 2, 5 or 10 such mutations could lead to seizures where none would alone. This complexity extends to the therapeutic domain: many drugs have multiple binding sites producing multiple effects which will require modeling to be fully understood.

\section{Multiscale modeling}

As epilepsy is characterized by recurrent seizures, one might imagine that we would build an epilepsy model directly out of a seizure model. However, the complexity of such a combined model makes it unattainable for the foreseeable future. More importantly, such a model would violate a central tenet of both mathematical and computer modeling: simplification. A large part of the art of modeling consists of deciding what to leave out. In computer modeling, we utilize the concept of multiscale modeling. Conceptually, multiscale modeling is familiar in biology: cell biology models depend on molecular biology models and so forth down to quantum mechanics. In biomedical science, we build hierarchies of models: models of models of models. A clinical disease is represented by one or more in vivo animal models, aspects of which can be further explored in vitro. An acute brain slice from an epileptic animal serves as a reduced model system for understanding the seizures in the source animal. Computer models may either be explicit models of one of these models or an attempt to translate the results of such models up to a higher modeling or the clinical level.

In the case of epilepsy, multiscale modeling can be envisioned across many different dimensions. First there is spatial scale. Models range from the single ion channel up to the level of brain areas. ${ }^{50,112}$ There is the temporal scale: modeling of interictal spikes (over a ms timescale), seizures (over seconds to minutes), drug treatments (over months) and disease evolution (over years). We can also model across and among the clinical axes (Box 1). For example, modeling seizure semiology would help us explain seizure spread. Similarly, simulation can evaluate neuronal network dynamics in the context of transitions between tonic and clonic activity. ${ }^{93}$ Modeling can also connect seizures to associated signs or underlying causes. Simulation extends to socioeconomic impact: public health models can be used to evaluate trade-offs between various treatments and quality of life or economic impact. 


\section{Computer modeling: static and dynamic}

Scientific model building is a set of techniques, ranging from scale models and verbal models to detailed taxonomies (the Linnean system), geometric relations (the periodic table), diagrams and schematics and mathematical models, as well as animal and in vitro models. ${ }^{52}$ In order to model seizures and epilepsy on a computer, we need to consider these existing models, both biological and ontological.

\section{Static models}

Computational neuroscience is a branch of computational systems biology $37,57,111,110$ _ utilizing two interlocking types of study: knowledge discovery and data-mining (KDD), and simulation. ${ }^{77} \mathrm{KDD}$ permits a search for patterns in static data and provides substrate and context for building simulations. ${ }^{15}, 16,76,120 \mathrm{KDD}$ can be used to explore both biological databases and the taxonomies developed for public health, health insurance and bibliographic purposes. ${ }^{26,27}$ As noted above, the complexity of epilepsy has blocked agreement on a taxonomy and classification systems. ${ }^{41,}{ }^{49}$ Formal taxonomies and ontologies developed through KDD may help clarify the aspects and subtypes of epilepsy explored through animal research and modeling.

In the context of KDD, a database is a computer model. The structure of a complex database (for example gene networks, cell signaling cascades, metabolic pathways) embodies the data, incorporating relations such as hierarchies, inheritance and lateral associations. KDD extracts information that would not be apparent through unmediated human reading of these models. 11, 22 Similarly, a formal ontology organizes data within a taxonomy with rules for linking, embedding or transforming concepts. ${ }^{27}$ Various qualitative models can be built from a database or ontology. Such models define phenomenology coarsely, in terms of classes, types or gross sizes.

Another type of static computer model, the graph model, generates and examines connectivity diagrams. Directed graphs, where $\mathrm{A} \rightarrow \mathrm{B}$ differs from $\mathrm{B} \rightarrow \mathrm{A}$, are used to define patterns of neuronal connectivity. A major distinction is made between random graphs (uniform connectivity probabilities) and small-world graphs with low average distance from any node to any other. ${ }^{137}$ Small world graphs often contain hubs (similar to the airline hub system). Graph theory has been used at the level of brain areas as well as neuronal networks and is further discussed below.

\section{Dynamic models}

Dynamical modeling involves loading equations describing change into a computer. These equations are numerically solved to provide precise predictions of how a complex system will evolve. Although computer modeling is a direct extension of mathematical modeling, it differs by itself being an experimental pursuit, yielding unexpected insights during exploration. ${ }^{161}$ Simulation produces large amounts of virtual data, complementing experimental data. The virtual data can then be data-mined, ${ }^{118}$ providing comparison with the original system, exploration of missing parameters, and development of new hypotheses. ${ }^{76,105}$ In this way, simulation and KDD are partnered in mutual support. ${ }^{90,} 98$

Dynamical models include stochastic (random) models such as Poisson models, Monte Carlo models, Markov models, and others. In these models intervals or instances are drawn randomly from a distribution. Markov models have been used to model seizure occurrence times ${ }^{117}$ and are also widely used to model ion channel transitions. ${ }^{148}$ Monte Carlo models are used to follow trajectories of individual molecules and ions at a synapse. ${ }^{50}$ 
The workhorse of dynamical modeling is the deterministic model, generally described by differential equations. For computerization, these equations are discretized in space and time (finite-difference approximations). Neurobiological examples of dynamical models include compartmental modeling and the Hodgkin-Huxley equations. ${ }^{43}, 67$. Another form of deterministic model is the event-driven model, which manages time discontinuously as it follows events that are consequent on prior events. Such models can be used to model spike cascades. ${ }^{6,}, 31,97,101,125,153$ I will now look at specific dynamical seizure and epilepsy models.

\section{Stochastic models}

Most scientists are quite familiar with a basic type of mathematical modeling, that of fitting data to a distribution. It is easy to turn the data-fitting process around to create ersatz data from statistical model parameters - for example the two parameters $(\mu, \sigma)$ of a Gaussian distribution - and create a simple stochastic model. Stochastic models may be used when a system is too complex to consider modeling the underlying details. They are also used when a system is subject to vagaries that cannot reasonably be modeled. Seizures are more likely to occur, for example, after missing a night's sleep. It is not feasible to model the behavioral or employment patterns that might lead to this. Stochastic modeling can be used to understand the clinical course of epilepsy and to investigate whether we can predict seizure onset.

\section{Predicting seizures}

Initial stochastic models of seizure occurrence times suggested that they followed a Poisson distribution. ${ }^{104}$ Subsequent clinical studies indicated that some patients will show deviations from this pattern through cyclicity (periodic seizure recurrence such as sometimes seen with menses) or seizure clustering. ${ }^{58,61,70}$ Further modeling research then suggested that the brains of some patients exhibit two states with different seizure occurrence probabilities -high and low corresponding respectively to seizure-prone and seizure-resistant periods. ${ }^{1,68,78} \mathrm{~A}$ twostate Markov model was also able to fit an animal seizure model, where a long period in the seizure-prone state was associated with a long period in the following seizure-resistant state. 140

Markov modeling has also been used to determine the adequacy of seizure prediction algorithms. ${ }^{162}$ A model for this purpose used 3 Markov brain states: Normal, Pre-seizure, and Seizure, with bidirectional transitions between any 2 states. The only state that was directly observable was Seizure. This was therefore a Hidden Markov Model: the other two states could not be directly observed from the data but were inferred through the model. In addition to the probabilistic transitions between states, there were also emission probabilities: the probability that a given state would be observed. For example, detection of Pre-seizure was associated with an emission probability. The model could therefore suggest where false positives (the algorithm indicating pre-seizure when the brain was normal) and false negatives (the algorithm not being triggered even though brain was pre-seizure) occurred.

From a neurobiological point of view, this model is interesting because it made explicit the notion of a pre-seizure state and made specific predictions about transitions into and out of this state. Meaningful seizure prediction (minutes ahead) will only be possible if such a state exists, something suggested by the ability of some patients to predict their own seizures up to a day ahead. ${ }^{60}$ Without a pre-seizure state, the most that can be accomplished is improvement in detecting seizure onset. This model demonstrated frequent Pre-seizure $\leftrightharpoons$ Seizure transitions, a possible cause of seizure clustering. ${ }^{61,}{ }^{62}$ Similarly, it demonstrated the Pre-seizure $\rightarrow$ Normal transitions whose probability would have to be increased by any prediction-triggered therapy. 


\section{Modeling clinical course}

Another study used modeling to follow clinical course (remission and relapse). ${ }^{7}$ A 3 -state Markov model fit the course of epilepsy in 602 children (Fig. 2). The model predicted that a subset (about 20\%) of patients would never remit. The proportion of patients expected to be in remission was predicted to be about $70 \%$ after $4-5$ years. These groups could then be analyzed as to their underlying diagnosis, connecting dynamics with disease definition (ontology). This model has prognostic value: we can give a parent some idea of the chance of remission once the child reaches school age. Additionally, this model showed that the probability of remaining in remission differed little with time to remission from 1-3 years. The probability was slightly reduced if the child took 4 years to remit. This result may have neurobiological implications. Clearly, epilepsy in the child's brain is a highly non-stationary process - the brain is continuously changing due both to the effects of seizures and to normal or abnormal developmental processes. One can imagine that there are vulnerable (critical) periods, in brain development or in epilepsy development, during which therapeutic interventions would be particularly efficacious. ${ }^{13}$

\section{Lumped deterministic models}

By contrast to stochastic models, deterministic models do not evolve randomly but are precisely determined by their initial conditions and can therefore offer precise predictions rather than probabilities. This precision is exemplified in a moon shot (a voyage from earth to moon), which is controlled through computer models that predict trajectories with an error of order meters over a distance of $\sim 384$ megameters. Unfortunately complex nonlinear systems such as the brain do not lend themselves to such precision. Nonlinearity implies that a small change can produce a big effect: for example, in the neuron a small current near the dynamic spike threshold will produce a spike. In a nonlinear dynamical system, this may lead to such sensitivity to initial conditions that tiny unobservable alterations in the initial state of the system will lead to far different outcomes. Thus a deterministic system can produce apparently random behavior, called chaos. ${ }^{55,147}$ This is how a computer produces random (actually pseudorandom) numbers. A moon shot, by contrast, is a nonlinear dynamical system that is neither complex (in the technical sense) nor chaotic.

A dynamical system is defined by equations (in the case of the moon shot, Newton's equations), parameters (the strength of gravity, the mass of the rocket), initial conditions (a location in Florida and zero velocity in the earth frame) and is described by the evolution of its state variables (position and velocity) along a trajectory. In some cases, a trajectory may lie on an attractor, making it resistant to perturbation. In neurobiology, the exemplary dynamical system is the 4-dimensional Hodgkin-Huxley system for action potential generation. Here the state variables are membrane voltage and levels of channel activation and inactivation and a given current injection (a parameter) results in the evolution of these variables along a stable trajectory that lies on an attractor.

The 4-dimensional Hodgkin-Huxley equation is a low-dimensional dynamical system. By contrast, hundreds of state variables are required to describe a neuron, even if we only evaluate membrane voltage generation, and millions more if we consider ion and peptide concentrations and proteomic cascades. A brain area would be described by the dynamics of very many neurons and glia and by the dynamics of the connections among them. Fortunately, system trajectories in such a high-dimensional system will not fill the high-dimensional space but will be confined to the lower-dimensional subspaces of attractors, just as water flows along lowlying paths rather than spreading across an entire landscape. Indeed, the enormous dynamical complexity of the brain, like its structural complexity, would be unmanageable if not organized into subsystems. The existence of widespread distinct oscillatory frequencies in the electroencephalogram (EEG) suggests that dynamical subsystems are detectable. Hence it is 
hypothesized that the enormous dimensionality of the brain produces trajectories that lie in much lower-dimensional subspaces that can then be modeled by equivalent low-dimensional dynamical systems.

Following this hypothesis, low-dimensional mean-field or lumped models have been developed to simulate the dynamics of a large ensemble of neurons (the lump). Depending on the model, this neural lump is interpreted to be a minicolumn, a column, a Brodmann area, a thalamic nucleus, etc. ${ }^{13}$ Most such models are based explicitly or loosely on Wilson and Cowan's 1972 model. $51,84,86,158$ The neural lump of the Wilson-Cowan model has two state variables excitable population firing and inhibitory population firing. Within a single lump of the model, excitatory and inhibitory populations interact to produce an oscillator, mathematically comparable to a mass bouncing on a spring, for which the 2 state variables are position and velocity. These state variables trade off sinusoidally: the extreme position (fully stretched spring) is associated with zero velocity. Similarly, in the Wilson-Cowan model, excitation and inhibition trade off so that periods of high inhibition are associated with minimal excitation. Connecting Wilson-Cowan oscillators via their excitatory outputs leads to a system of coupled oscillators. $^{24,}$ 43, $45,51,136,146,157,160$

\section{A lumped model of absence}

Over the years, a series of epilepsy and seizure models have been based on variations of the Wilson-Cowan approach. ${ }^{82}, 121,138,154,159$ Because these models are low-dimensional, they are amenable to graphical explorations of their trajectories. Fig. 3 shows a slice of state-variable space (called state space or phase space) in a model of absence epilepsy. An analogy would be as if we were looking down at a ball rolling in broad-rimmed bowl. The ball can roll around on the rim (outer trajectories) as well as rolling around inside the bowl (center trajectories): the centre and rim of the bowl represent attractors. An outer trajectory is a seizure. The graph on the left shows the normal model in which the attractors are well separated - it would take a lot of random activity (noise) to shift the system out of its normal attractor and into the pathological attractor. On the right, a parameter change (such as increase in external drive or alteration in intrinsic time constants) has deformed the attractors. This expands the attractors and lowers the "energy barrier" that separates them. Now, random transitions between attractors will occur more frequently, leading to seizures. ${ }^{85,139}$

This deterministic model of absence epilepsy produces dynamics that suggest stochastic seizure causation: the attractors in the vulnerable individual lie so close together that minor perturbations can trigger a seizure. Being randomly triggered, these seizures would not be predictable from the EEG - there is no pre-seizure state. This model suggests that some kinds of epilepsy will not be amenable to seizure prediction. However, triggering factors could still be identified and avoided. ${ }^{47,} 72$

\section{A lumped model of MTLE}

A different class of seizure transitions have been identified using a similar low-dimensional model applied to MTLE. ${ }^{155}$ This model uses an archicortical rather than thalamocortical organization and is able to successfully reproduce a variety of patterns seen in patients (Fig. 4). Fig. 4A compares patterns of activity from this lumped cortical model to patterns recorded from hippocampal depth electrodes in an epilepsy patient undergoing evaluation for surgery.

The activity patterns in Fig. 4A are produced by the parameter setsillustrated in the twodimensional slice of parameter space illustrated in Fig. 4B. Changes in activity patterns can be produced by changes in parameters which will deform existing attractors or produce new ones. A sequence of parameter transitions shown by the arrow in Fig. 4B would produce passage 
from normal activity, through a pre-seizure state, into a seizure. In contrast to the case in Fig. 3 , such a seizure would be predictable: there is a defined pre-seizure state that could be detected.

Although I have emphasized the difference between state variables and parameters, it is important to note that the movement in parameter space hypothesized above is itself a dynamic. In order to model these dynamics, it would be necessary to promote this inhibitory parameter to a state variable, one with far slower time constants than those of the existing state variables. In fact, the fast dynamics of brain activity are continually altered by the slower dynamics of synaptic and cellular plasticity. ${ }^{80}$ Similarly, as we will discuss in the next section, these dynamics are in turn altered by the still slower dynamics of development, of cell growth and death, of synaptic sprouting and pruning.

\section{Detailed deterministic models: neuronal networks}

Detailed neuronal modeling has been one of the most productive areas of neural modeling and of neural modeling applied to epilepsy. Unlike the lumped models described above, detailed neural models try to incorporate many of the details that we know about the nervous system. This should permit greater verisimilitude. However, this goal is limited by three factors. First, we don't know enough (particularly discouraging is the lack of a wiring diagram). Second, we don't have enough computer power. Third, a model generally needs to perform some simplification to be useful (see above).

Detailed modeling is performed across a wide range of spatial scales, from single synapse to cortical column to whole brain. ${ }^{50,73}$ The best defined epilepsies neurobiologically are those due to ion channel abnormalities. Many anticonvulsants function in part by altering channel conductances or kinetics. Modeling has shown how alterations in channel dynamics (molecular level) can change neural firing patterns (cell level). ${ }^{96,134}$

Much effort in detailed modeling has taken place at the network level, following pioneering

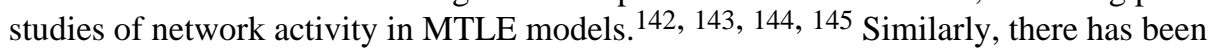
considerable progress in modeling the thalamocortical interactions that give rise to absence seizures. ${ }^{36}$ One notable success involved the computational prediction of activity entrainment into pathologic hypersynchronized oscillations at around $3 \mathrm{~Hz} .^{2}, 14,34$ Computational load generally limits the use of detailed models to depictions of seizures or of interictal events rather than to the longer time-scales required to directly model epilepsy. However, just as with the lumped MTLE model above, detailed models can assume that slower dynamics have taken place without explicitly modeling them.

\section{Connectivity predicts dynamics in dentate gyrus}

Given the prevalence of MTLE, the hippocampus has been a focus of basic investigation. The dentate gyrus (DG) and hilus in particular demonstrate a wide variety of alterations during epileptogenesis in both patients and animals. ${ }^{38,} 69,100,114,115,115,141$ The variety of effects include cell death with attendant synaptic pruning and cell birth or axonal sprouting with addition of synapses. Excitatory sprouting may be onto excitatory cells, inhibitory cells, or both. ${ }^{131}$

Several studies have focused on the consequences of axonal sprouting and cell death for hyperactivity in dentate gyrus..$^{92,} 119$ In a recent series of models, dynamic simulation was coupled with a database model and a formal graph model. ${ }^{19}, 106$ These interlocking static and dynamic models were used not only to understand and predict physiology but also to highlight gaps in the anatomical record and make predictions about wiring. ${ }^{39,}$ 105, 106, 126 
The simulation showed that excitatory-excitatory sprouting led to long-duration activation in models that would otherwise show minimal activity beyond the initial stimulation period. However, maximum activation was seen at an intermediate level of pathology, involving both sprouting and hilar cell loss. Furthermore, although activity propagation was dependent on the presence of long-range excitatory mossy cells in the hilus, only a relatively few mossy cells had to be present in order to sustain activity. These simulation results are in agreement with histological results that indicate that some mossy cells frequently survive in the sclerotic hippocampus of temporal lobe epilepsy patients.

Further analysis of the directed graph model suggested that an effect of the pathogenic process may be to make the network more "small world." 106 Small world networks could provide hubs to distribute seizure activity extensively due to their characteristic short path lengths between nodes. ${ }^{136,137,152}$ The study suggested that sprouting might lead to a preponderance of such neuronal hubs due to rewiring. These hubs could be produced by projections onto granule cells having hilar basal dendrites. ${ }^{106}$

\section{A model of disexcitatory ictogenesis}

Computer modeling is perhaps most useful, and certainly most provocative, when the emergent properties of a system are contrary to expectations. ${ }^{89}$ For example, a long-held general model of epilepsy is that normal activity represents a homeostatic balance between excitation and inhibition and that seizures represent a shift towards excessive excitation. ${ }^{127}$ This general picture undoubtedly has some validity: many proconvulsants block inhibition or augment excitation. However, the notion of excitation-inhibition balance is not always applicable. Absence seizures, for example, are dependent on inhibitory (hyperpolarizing) influences that are effectively excitatory in thalamocortical cells due to this cell type's burst rebound from hyperpolarization. $4,32,35,91,30$ Inhibition has been shown to play a variety of roles in other systems as well. ${ }^{95,28,10}$

With advances in computing it is now possible to use supercomputers to run massive simulations, again with the hope of providing greater verisimilitude by more closely approximating the large numbers of cells in brain areas. ${ }^{63,64,65,73,99,103,142} \mathrm{~A}$ recent series of studies used such models to explore coupling both between cortical layers and among neighboring cortical columns or areas. ${ }^{149,}{ }^{150} \mathrm{Fig}$. 5 shows a path from normal activity to seizure in a format comparable to that of Fig. 4. However, the direction of change, and hence the conclusion, are entirely different. According to this detailed model, a reduction in excitation, rather than a reduction in inhibition, caused the transition to seizure. Spurred by these paradoxical findings, the investigators subsequently demonstrated disexcitatory ictogenesis in mouse neocortical slices. ${ }^{149}$

What at first seems like contradiction between the detailed and lumped models - one showing disinhibitory and the other disexcitatory ictogenesis -does not represent a disagreement between models but instead again illustrates the complexity of seizure causality. A particular model, or a particular parameter range, is likely to be relevant to a particular seizure type or even to a particular patient. Referring back to Fig. 1, it is to be expected that the vast numbers of possible contributors to seizures and epilepsy leave room for a number of surprising dynamical mechanisms. For example, it has been shown experimentally that combining two "epilepsy genes" can produce an animal with reduced seizure propensity ${ }^{56}$ Multiple mechanisms will similarly coexist in patients, explaining for example how a particular pharmacotherapeutic treatment could treat one of the patient's seizure patterns while either not affecting or even exacerbating another seizure pattern. $53,93,151$

A disadvantage of detailed modeling is that it is difficult to understand the dynamics in terms of specific attractors; we cannot visualize the high-dimensional space in which these attractors 
exist. This lack of detailed dynamical understanding reduces the explanatory power of the models by making attractor transitions opaque to our current visualization tools. A compensatory advantage of the detailed models is that one can look directly at single cell firing (Fig. 5C) and compare this with intra- or extracellular recordings in vivo or in slice. An additional advantage is that one can test specific drug effects in the simulation by including explicit models of ion channels or synaptic mechanisms.

\section{Future directions}

This review has shown that epilepsy and seizure modeling can be used at a variety of levels to assist in our understanding of the various clinical aspects of the disease: prognostication, prediction, classification, therapeutics, and diagnosis. I have shown how a model of pediatric disease progression can be used to provide prognostic information for patient subgroups. It would be particularly valuable to directly connect models of this sort with taxonomic databases and ontologies as well as to genetic databases in order to correlate these various clinical sources with patient outcome. In this way, ontologic modeling and KDD can work to develop new classifications and define syndromes and subsyndromes. ${ }^{12,}$ 16, 37, 57, 108

Successful seizure prediction will require a combination of further modeling and experimental work. Seizure prediction will not only permit development of implantable seizure-termination devices, but also devices that simply alert patients to periods of high seizure probability. However, as suggested by the absence epilepsy model of Fig. 3, some seizure types are likely to have no pre-seizure state and be therefore unpredictable. We have seen how models can interface with seizure prediction algorithms. Similarly, we could develop computer models that interact directly with ongoing clinical seizure monitoring in order to gradually learn a model of a particular patient's seizures.

We have suggested that the multifactorial causation of epilepsy, exemplified in the river metaphor (Fig. 1), can best be approached by computer models that are able to encapsulate the many conspiring and counteracting causes and mitigating or exacerbating influences. This complexity also extends to the therapeutic domain, where many drugs are noted to have multiple binding sites and multiple effects. This complexity has sometimes been downplayed by calling the drugs "dirty," in presumption that the additional binding is likely to be a cause of undesirable side effects while a single primary binding site is responsible for the therapeutic effect. However, in many cases, dirtiness may be a critical aspect of drug efficacy. ${ }^{122}$, 123 , ${ }^{124}$ Development of anticonvulsant drugs will benefit from modeling of such synergistic effects. Currently, rational pharmacotherapeutics is done by designing ligands for specific receptors. Rational pharmacotherapeutics will be able to utilize detailed computer modeling to also determine which receptors should be targeted together.

A major area of computational systems biology has not been discussed here: the dynamical simulation of genomics, proteomics and cellular physiomics (signal transduction pathways) to permit study of alterations at the cell biology level. ${ }^{29,} 79$ This research has enormous importance for the synaptic and cellular plasticity that likely underlies many kinds of epilepsy. It has not been discussed because thus far very little work in this area has been applied to epilepsy.

An exciting aspect of computational neuroscience is its accessibility to researchers with widely differing backgrounds (Box 2). It has recently been suggested that "The application of systems biology to medical practice is the future of medicine." 77 With wide participation, advances in computer modeling, and clinical application of results, this prediction may come early to epilepsy. 


\section{Box 1: The epilepsy axes}

Of late much effort, and much argument, has gone into revising epilepsy taxonomy and classification. ${ }^{40}$ The new classification, while not officially accepted by the International League Against Epilepsy or even by the committee that designed it, is a step forward from the point of view of computationalists and for neuroscientists in general. Rather than lumping etiology, semiology and syndromology together, the new classification separates these and others out into axes in the manner of the psychiatric classifications promulgated under the auspices of the various editions of the Diagnosis and Statistical Manuals (DSMs). Axis 1 describes "ictal semiology" - what do the patient's seizures look like clinically in terms of signs (observable manifestations) and symptoms (patient complaints). This axis strives for reproducibility by using a standard "Glossary of Descriptive Terminology." Axis 2 redescribes the seizure types using a somewhat more global and traditional viewpoint, with descriptors that include "tonic-clonic" and "typical absence." These first two axes are therefore not orthogonal. Axis 3 provides syndromic diagnosis where possible, including a list of particular symptom complexes which have in some cases been shown to have particular chromosomal or even precise genetic linkage. Axis 4 provides a descriptor for underlying etiology (cause). This allows for precise definition of those syndromes that are known at a molecular (channel, neurotransmitter or receptor) level. Again Axes 3 and 4, are not orthogonal. Axis 5 describes the socioeconomic impact of the patients disorder. An alternative axial framework also provides axes for seizure spread patterns and for seizure frequency. ${ }^{75,} 83,87$

Ideally a multidimensional taxonomic system should permit us to place an individual patient in a particular point in the state space defined by the measures on each axis. By analogy with dynamical systems, one could consider the patient's clinical definition moving in this space over years of disease evolution, treatment, remission and relapse.

\section{Box 2: How modeling is done}

Compared to most subspecialty areas of neuroscience, computational modeling is notable for its accessibility, particularly given today's computer-literate scientific community. While a neuroscientist or epileptologist would hardly expect to casually pick up electron microscopy, he or she could spend a weekend learning and exploring a computer model. Most computational researchers are quite happy to share their computer code. Hundreds of models, including some of those discussed here, are available for immediate download at ModelDB. ${ }^{66}$ Several software packages are commonly used to run simulations (see Further Information). Most of the stochastic and low-dimensional models are done in Matlab, a commercial general purpose engineering and simulation environment, or Octave, its free counterpart. ${ }^{54}$ Low-dimensional deterministic models can also be run using Xppaut, a freely available package. ${ }^{44}$ Detailed computer models are generally run using specialized software such as Neuron and Genesis. ${ }^{18,23}$ A variety of other neural simulators, at various levels, are also available. ${ }^{21}$ Brette et al. provide a recent review. ${ }^{20}$

\section{Box: Further information}

Task force on epilepsy classification and terminology web site (www.ilae-epilepsy.org/Visitors/Centre/ctf) provides a full description of the proposed axial classification scheme for epilepsy. 
The Modeld $b$ website (senselab.med.yale.edu/senselab/ModelDB) is a database of runnable models producing one or more of the figures in a published modeling paper. This is often a good starting point for further explorations.

Matlab (commercial) and Octave (free) are similar general mathematical tools that permit ready exploration of basic concepts and simple simulations. These can be accessed at www.mathworks.com and www.gnu.org/software/octave respectively.

Neuron is a general neural simulation system which is freely available at www.neuron.yale.edu.

$X p p$ is a general dynamical system simulator which is freely available at www.math.pitt.edu/ bard/xpp/xpp.html

\section{Biography}

Author Biography

William Lytton is a neurologist practicing at Kings County Hospital and researching computational neuroscience at SUNY Downstate. He is the author of "From Computer to Brain," a basic introduction to computational neuroscience.

\section{Glossary}

attractor, The set of stable trajectories of a dynamical system in state-space. If a trajectory is perturbed away from an attractor it will tend to move back to the attractor.

cortical minicolumn, A group of cortical cells that interact with each other more than they do with neurons in neighboring columns. While columnar structure was originally identified physiologically as groups of neurons with shared properties, it has since been sought anatomically and variously identified as groups of from 100-200 neurons ( 30 $\mu \mathrm{m}$ across). discretization, Dividing continuous time into timesteps, or continuous space into segments or compartments, in order to simulate continuous reality in the discontinuous words of computer memory.

dynamical model, Computer or physical model that reproduces change in an experimental observable. In the case of dynamical models of motion these changes would be in position and velocity.

finite-difference approximation, Approximating the infinitesimal changes of continuous curves (in time or space) with a finite change based on the curve's values at a discrete timestep or spatial interval. See discretization.

focal seizure, A seizure that starts at a particular location in the brain.

generalized seizure, A seizure that appears to start simultaneously across cortical sites.

lumped model, A model that approximates the activity of a large ensemble of neurons by a single state variable that typically represents the proportion of neurons that are active at a given time.

Markov model, A stochastic model that uses a series of connected states with trnasition probabilities between them.

mean-field approximation, An approximation used when large numbers of elements (e.g., neurons) make it impracticable to model the influence of each element individually. Instead, the effect of a large ensemble of elements is estimated as a field whose influence is widely felt. See lumped model.

Monte-Carlo model, A stochastic model that uses repeated random sampling from one or more distributions. 
parameter, In a computer model, the constant values in the set of equations describing the model. These values are set by the user and determine model behavior.

parameter space, The definition of the $m$ parameters of a system as a point in an $m$-dimensional space.

Poisson model, A stochastic model that generates time intervals that are drawn independently from a Poisson distribution. The Poisson distribution is the limiting case of the binomial distribution for large $n$ (number of events) and small $p$ (probability of event occurrence). scale model, A small physical model of an object with correct proportions.

secondary generalization, A process whereby an initially focal seizure spreads to involve the entire brain.

seizure semiology, The detailed study of the progress of a seizure.

separatrix, An unstable equilibrium that separates 2 attractors in a dynamical system. state space, The dimensionality of a dynamic system; the current state of the system can be described as a point in state-space. Also called phase space.

state variable, In a dynamical model, the values that change with time. In the Hodgkin-Huxley model these are voltage $V$, sodium channel activation state $m$ and inactivation state $h$ and potassium channel activation state $n$.

stochastic model, A computer model that attempts to replicate phenomenology by drawing exemplars (which may be locations or time intervals) from a probability distribution. The prototypical example is the model of Brownian motion.

systems biology, The analysis of element interactions in biological systems. Due to the complexity of these systems, the computer is often used as a tool for analysis and simulation. Objects of study include metabolic and expression pathways but extend up to the study of macroscopic systems. The goal is to insert the results of reductionist study back into the systems from which they were extracted.

tonic-clonic, A common pattern of convulsion involving a phase of contraction of extensor muscles (tonic) followed by alternating flexor-extensor contractions (clonic phase). trajectory, In a dynamical model, the path followed by the $n$ state variables through the $n$ dimensional state space. This is a higher-dimensional generalization of the notion of trajectory as commonly used to describe motion. However, trajectories in models of motion include velocities as well as locations.

verbal model, An informal descriptive explanation of an object or phenomenon.

\section{References}

[1]. Albert PS. A two-state Markov mixture model for a time series of epileptic seizure counts. Biometrics 1991;47:1371-1381. [PubMed: 1786324]

[2]. Bal T, Debay D, Destexhe A. Cortical feedback controls the frequency and synchrony of oscillations in the visual thalamus. J Neurosci 2000;20:7478-7488. [PubMed: 11007907]

[3]. Baraban SC, Dinday MT, Castro PA, Chege S, Guyenet S, Taylor MR. A large-scale mutagenesis screen to identify seizure-resistant zebrafish. Epilepsia 2007;48:1151-1157. [PubMed: 17521353]

[4]. Bazhenov M, Timofeev I, Steriade M, Sejnowski TJ. Computational models of thalamocortical augmenting responses. Journal of Neuroscience 1998;18:6444-6465. [PubMed: 9698334]

[5]. Bear DM, Fedio P. Quantitative analysis of interictal behavior in temporal lobe epilepsy. Archives of Neurology 1977;34:454-467. [PubMed: 889477]

[6]. Beggs JM, Plenz D. Neuronal avalanches in neocortical circuits. Journal of Neuroscience 2003;23:11167-11177. [PubMed: 14657176]

[7]. Berg AT, Lin J, Ebrahimi N, Testa FM, Levy SR, Shinnar S. Modeling remission and relapse in pediatric epilepsy: application of a Markov process. Epilepsy Res 2004;60:31-40. [PubMed: 15279868]

[8]. Berg AT, Shinnar S. Do seizures beget seizures? an assessment of the clinical evidence in humans. Journal of Clinical Neurophysiology 1997;14:102-110. [PubMed: 9165405] 
[9]. Berkovic, SF.; Reutens, DC.; Andermann, E.; Andermann, F. The epilepsies: specific syndromes or a neurobiological continuum?. In: Wolf, P., editor. Epileptic Seizures and Syndromes. John Libbey Eurotext; Paris: 1994. p. 25-37.chapter 5

[10]. Bernard C. Dogma and dreams: experimental lessons for epilepsy mechanism chasers. Cell Mol Life Sci 2005;62:1177-1181. [PubMed: 15905965]

[11]. Bertone P, Gerstein M. Integrative data mining: the new direction in bioinformatics. IEEE Engineering in Medicine \& Biology Magazine 2001;20:33-40. [PubMed: 11494767]

[12]. Blois MS. Medicine and the nature of vertical reasoning. N Engl J Med 1988;318:847-851. [PubMed: 3352667]

[13]. Blumenfeld H, Klein JP, Schridde U, Vestal M, Rice T, Khera DS, Bashyal C, Giblin K, PaulLaughinghouse C, Wang F, Phadke A, Mission J, Agarwal RK, Englot DJ, Motelow J, Nersesyan H, Waxman SG, Levin AR. Early treatment suppresses the development of spike-wave epilepsy in a rat model. Epilepsia 2008;49:400-409. [PubMed: 18070091]

[14]. Blumenfeld H, McCormick DA. Corticothalamic inputs control the pattern of activity generated in thalamocortical networks. J Neurosci 2000;20:5153-5162. [PubMed: 10864972]

[15]. Bornholdt S. Systems biology. less is more in modeling large genetic networks. Science 2005;310:449-451. [PubMed: 16239464]

[16]. Bosl WJ. Systems biology by the rules: hybrid intelligent systems for pathway modeling and discovery. Bmc Syst Biol 2007;1:13. [PubMed: 17408503]

[17]. Bouwman BM, Suffczynski P, Lopes da Silva FH, Maris E, van Rijn CM. Gabaergic mechanisms in absence epilepsy: a computational model of absence epilepsy simulating spike and wave discharges after vigabatrin in wag/rij rats. Eur J Neurosci 2007;25:2783-2790. [PubMed: 17561843]

[18]. Bower, J.; Beeman, D. The Book of Genesis. Vol. 2 edition. Springer; New York: 1998.

[19]. Bradley DC, Mascaro M, Santhakumar S. A relational database for trial-based behavioral experiments. J Neurosci Methods 2005;141:75-82. [PubMed: 15585290]

[20]. Brette R, Rudolph M, Carnevale T, Hines M, Beeman D, Bower JM, Diesmann M, Goodman PH, Harris FCJ, Zirpe M, Natschlger T, Pecevski D, Ermentrout B, Djurfeldt M, Lansner A, Rochel O, Vieville T, Muller E, Davison A, El Boustani S, Destexhe A. Simulation of networks of spiking neurons: a review of tools and strategies. J Comput Neurosci 2007;23:349-398. [PubMed: 17629781]

[21]. Cannon RC, Gewaltig MO, Gleeson P, Bhalla US, Cornelis H, Hines ML, Howell FW, Muller E, Stiles JR, Wils S, De Schutter E. Interoperability of neuroscience modeling software: current status and future directions. Neuroinformatics 2007;5:127-138. [PubMed: 17873374]

[22]. Cannon RC, Howell FW, Goddard NH, De Schutter E. Non-curated distributed databases for experimental data and models in neuroscience. Network: Computation in Neural Systems 2002;13 (3):415-428.

[23]. Carnevale, NT.; Hines, ML. The NEURON Book. Cambridge; New York: 2006.

[24]. Chakravarthy N, Sabesan S, Iasemidis L, Tsakalis K. Controlling synchronization in a neuron-level population model. Int J Neural Syst 2007;17:123-138. [PubMed: 17565508]

[25]. Chang BS, Lowenstein DH. Epilepsy. N Engl J Med 2003;349:1257-1266. [PubMed: 14507951]

26. An excellent brief introduction to the many epilepsies and to current clinical and experimental issues.

[26]. Chute CG. Clinical classification and terminology: some history and current observations. J Am Med Inform Assoc 2000;7:298-303. [PubMed: 10833167]

[27]. Chute CG. Medical concept representation. Medical Informatics. Knowledge Management and Data Mining in Biomedicine. US: Springer 2005;8:163-182.

[28]. Cossart R, Bernard C, Ben-Ari Y. Multiple facets of GABAergic neurons and synapses: multiple fates of GABA signalling in epilepsies. Trends Neurosci 2005;28:108-115. [PubMed: 15667934]

30. A useful introduction to the roles and controversies of GABA signaling.

[29]. Crampin EJ, Halstead M, Hunter P, Nielsen P, Noble D, Smith N, Tawhai M. Computational physiology and the physiome project. Exp Physiol 2004;89:1-26. [PubMed: 15109205]

[30]. Crunelli V, Leresche N. Childhood absence epilepsy: genes, channels, neurons and networks. Nat Rev Neurosci 2002;3:371-382. [PubMed: 11988776] 
33. Review traces absence manifestations from genes to the whole animal.

[31]. Delorme A, Thorpe SJ. Spikenet: an event-driven simulation package for modelling large networks of spiking neurons. Network-Computation in Neural Systems 2003;14:613-627.

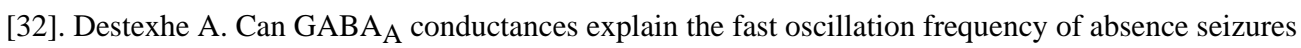
in rodents? European Journal of Neuroscience 1999;11:2175-2181. [PubMed: 10336687]

[33]. Destexhe A. Spike-and-wave oscillations. Scholarpedia 2007;2:1402.http://www.scholarpedia.org/article/Spike-and-wave_oscillations

[34]. Destexhe A, Contreras D, Steriade M. Spatiotemporal analysis of local field potentials and unit discharges in cat cerebral cortex during natural wake and sleep states. J Neurosci 1999;19:45954608. [PubMed: 10341257]

[35]. Destexhe A, McCormick DA, Sejnowski TJ. Thalamic and thalamocortical mechanisms underlying 3 Hz spike-and-wave discharges. Prog Brain Res 1999;121:289-307. [PubMed: 10551033]

[36]. Destexhe, A.; Sejnowski, TJ. Thalamocortical Assemblies. Vol. 49. Oxford U. Press; New York: 2001. of Monographs of the Physiological Society

40. Application of paired experiment and modeling to the dynamics behind absence seizures and sleep spindles.

[37]. Dubitzky W. Understanding the computational methodologies of systems biology. Brief Bioinform 2006;7:315-317. [PubMed: 17132621]

[38]. Dudek FE, Sutula TP. Epileptogenesis in the dentate gyrus: a critical perspective. Prog Brain Res 2007;163:755-773. [PubMed: 17765749]

[39]. Dyhrfjeld-Johnsen J, Santhakumar V, Morgan RJ, Huerta R, Tsimring L, Soltesz I. Topological determinants of epileptogenesis in large-scale structural and functional models of the dentate gyrus derived from experimental data. J Neurophysiol 2007;97:1566-1587. [PubMed: 17093119]

[40]. Engel J. ILAE classification of epilepsy syndromes. Epilepsy Res 2006;70:S5-S10. [PubMed: 16822650]

[41]. Engel J. Report of the ILAE classification core group. Epilepsia 2006;47:1558-1568. [PubMed: 16981873]

[42]. Engel J, et al. A proposed diagnostic scheme for people with epileptic seizures and with epilepsy: report of the ILAE task force on classification and terminology. Epilepsia 2001;42:796-803. [PubMed: 11422340]

[43]. Ermentrout B. Neural networks as spatio-temporal pattern-forming systems. Rep Prog Phys 1998;61:353-430.

[44]. Ermentrout, B. Simulating, Analyzing, and Animating Dynamical Systems: A Guide to Xppaut for Researchers and Students. Society for Industrial Mathematics; Philadelphia: 2002.

[45]. Ermentrout B, Saunders D. Phase resetting and coupling of noisy neural oscillators. J Computational Neuroscience 2006;20:179-190.

[46]. Feil B, Fauser S, Wuwer Y, Glocker FX, Schulze-Bonhage A. Changes in intracortical excitability after successful epilepsy surgery. Epilepsy Res. 2008

[47]. Ferlazzo E, Zifkin BG, Andermann E, Andermann F. Cortical triggers in generalized reflex seizures and epilepsies. Brain 2005;128:700-710. [PubMed: 15728654]

[48]. Fisher RS, Emde B, Blume W, Elger C, Genton P, Lee P, Engel J. Epileptic seizures and epilepsy: definitions proposed by the international league against epilepsy (ILAE) and the international bureau for epilepsy (IBE). Epilepsia 2005;46:470-472. [PubMed: 15816939]

[49]. Fisher RS, Wolf P, Engel J, Lüders H, Najm IM, Wyllie E, Berg AT, Blackstone NW, Avanzini G. Of cabbages and kings: some considerations on classifications, diagnostic schemes, semiology, and concepts. Epilepsia 2003;44:1-13.

[50]. Franks KM, Bartol TM, Sejnowski TJ. A Monte Carlo model reveals independent signaling at central glutamatergic synapses. Biophys J 2002;83:2333-2348. [PubMed: 12414671]

[51]. Freeman WJ. Models of the dynamics of neural populations. Electroencephalogr Clin Neurophysiol Suppl 1978;34:9-18. [PubMed: 285858]

[52]. Frigg, Roman; Hartmann, Stephan. Models in science. In: Zalta, Edward N., editor. The Stanford Encyclopedia of Philosophy. 2008 Spring. 
[53]. Gayatri NA, Livingston JH. Aggravation of epilepsy by anti-epileptic drugs. Dev Med Child Neurol 2006;48:394-398. [PubMed: 16608550]

[54]. Gilat, A. MATLAB: An Introduction with Applications. Vol. 3 edition. Wiley; NY: 2008.

[55]. Glass, L.; Mackey, MC. From clocks to chaos: the rhythms of life. Princeton: 1988.

[56]. Glasscock E, Qian J, Yoo JW, Noebels JL. Masking epilepsy by combining two epilepsy genes. Nat Neurosci 2007;10:1554-1558. [PubMed: 17982453]

61. A remarkable case of genetic nonlinearity: seizure gene A + seizure gene B $\rightarrow$ reduced seizures.

[57]. Goel G, Chou IC, Voit EO. Biological systems modeling and analysis: a biomolecular technique of the twenty-first century. J Biomol Tech 2006;17:252-269. [PubMed: 17028166]

[58]. Haut SR. Seizure clustering. Epilepsy Behav 2006;8:50-55. [PubMed: 16246629]

[59]. Haut SR, Bigal ME, Lipton RB. Chronic disorders with episodic manifestations: focus on epilepsy and migraine. Lancet Neurol 2006;5:148-157. [PubMed: 16426991]

[60]. Haut SR, Hall CB, Le V, Lipton RB. Can patients with epilepsy predict their seizures. Neurology 2007;68:262-266. [PubMed: 17242331]

[61]. Haut SR, Lipton RB, LeValley AJ, Hall CB, Shinnar S. Identifying seizure clusters in patients with epilepsy. Neurology 2005;65(8):1313-1315. [PubMed: 16247068]

[62]. Haut SR, Shinnar S, Moshe SL. Seizure clustering: Risks and outcomes. Epilepsia 2005;46:146149. [PubMed: 15660781]

[63]. Hereld M, Stevens RL, Drongelen W, Lee HC. Developing a petascale neural simulation. Conf Proc IEEE Eng Med Biol Soc 2004;6:3999-4002. [PubMed: 17271175]

[64]. Hereld M, Stevens RL, Lee HC, van Drongelen W. Framework for interactive million-neuron simulation. J Clin Neurophysiol 2007;24:189-196. [PubMed: 17414975]

[65]. Hereld M, Stevens RL, Teller J, van Drongelen W. Large neural simulations on large parallel computers. Int. J. for Bioelectromagnetism 2005;7:44-46.

[66]. Hines ML, Morse T, Migliore M, Carnevale NT, Shepherd GM. Modeldb: a database to support computational neuroscience. J Comput Neurosci 2004;17:73-77.

[67]. Holmes W, Rall W. Estimating the electrotonic structure of neurons with compartmental models. J Neurophysiol 1992;68:1438-1452. [PubMed: 1432091]

[68]. Hopkins A, Davies P, Dobson C. Mathematical models of patterns of seizures. their use in the evaluation of drugs. Arch Neurol 1985;42:463-467. [PubMed: 3888154]

[69]. Houser CR, Miyashiro JE, Swartz BE, Walsh GO, Rich JR. Altered patterns of dynorphin immunoreactivity suggest mossy fiber reorganization in human hippocampal epilepsy. J Neurosci 1990;10:267-282. [PubMed: 1688934]

[70]. Iasemidis LD, Olson LD, Savit RS, Sackellares JC. Time dependencies in the occurrences of epileptic seizures. Epilepsy Research 1994;17:81-94. [PubMed: 8174527]

[71]. ILAE. Proposal for revised classification of epilepsies and epileptic syndromes. commission on classification and terminology of the International League Against Epilepsy. Epilepsia 1989;30:389-399. [PubMed: 2502382]

[72]. Inouye Y. Higher brain function as precipitant of seizure. Neurol Asia 2007;12:1-5.

[73]. Izhikevich EM, Edelman GM. Large-scale model of mammalian thalamocortical systems. Proc Nat Acad Sci USA 2008;105:3593-3598. [PubMed: 18292226]

[74]. Kalynchuk LE. Long-term amygdala kindling in rats as a model for the study of interictal emotionality in temporal lobe epilepsy. Neuroscience \& Biobehavioral Reviews 2000;24:691-704. [PubMed: 10974352]

[75]. Kellinghaus C, Loddenkemper T, Najm IM, Wyllie E, Lineweaver T, Nair DR, Lüders HO. Specific epileptic syndromes are rare even in tertiary epilepsy centers: a patient-oriented approach to epilepsy classification. Epilepsia 2004;45(S1):268-275. [PubMed: 15009229]

[76]. King RD, Garrett SM, Coghill GM. On the use of qualitative reasoning to simulate and identify metabolic pathways. Bioinformatics 2005;21:2017-2026. [PubMed: 15647297]

[77]. Kitano H. Computational systems biology. Nature 2002;420:206-210. [PubMed: 12432404]

[78]. Le ND, Leroux BG, Puterman ML. Exact likelihood evaluation in a Markov mixture model for time series of seizure counts. Biometrics 1992;48:317-323. [PubMed: 1581489] 
[79]. Le Novere N. The long journey to a systems biology of neuronal function. BMC Systems Biology 2007;1:28. [PubMed: 17567903]

[80]. Lemasson G, Marder E, Abbott LF. Activity-dependent regulation of conductances in model neurons. Science 1993;259:1915-1917. [PubMed: 8456317]

86. A classic modeling study demonstrating the interaction of fast and slow processes.

[81]. Lennox, WG.; Lennox, MA. Epilepsy and related disorders. Little Brown; NY: 1960.

[82]. Liley DT, Bojak I. Understanding the transition to seizure by modeling the epileptiform activity of general anesthetic agents. J Clin Neurophysiol 2005;22:300-313. [PubMed: 16357635]

[83]. Loddenkemper T, Kellinghaus C, Wyllie E, Najm IM, Gupta A, Rosenow F, Lüders H. A proposal for a five-dimensional patient-oriented epilepsy classification. Epileptic Disord 2005;7:308-316. [PubMed: 16338673]

[84]. Lopes, da, Silva FH, Hoeks A, Smits H, Zetterberg LH. Model of brain rhythmic activity. the alpharhythm of the thalamus. Kybernetik 1974; 15:27-37. [PubMed: 4853232]

[85]. Lopes da Silva FH, Blanes W, Kalitzin SN, Parra J, Suffczynski P, Velis DN. Dynamical diseases of brain systems: different routes to epileptic seizures. IEEE Trans Biomed Eng 2003;50:540-548. [PubMed: 12769430]

92. An excellent review from the lumped perspective.

[86]. Lopes da Silva FH, van Rotterdam A, Barts P, van Heusden E, Burr W. Models of neuronal populations: the basic mechanisms of rhythmicity. Prog Brain Res 1976;45:281-308. [PubMed: 1013341]

[87]. Luders H, Acharya J, Baumgartner C, Benbadis S, Bleasel A, Burgess R, Dinner DS, Ebner A, Foldvary N, Geller E, Hamer H, Holthausen H, Kotagal P, Morris H, Meencke HJ, Noachtar S, Rosenow F, Sakamoto A, Steinhoff BJ, Tuxhorn I, Wyllie E. Semiological seizure classification. Epilepsia 1998;39:1006-1013. [PubMed: 9738682]

[88]. Luhmann HJ, Mittmann T, Luijtelaar G, Heinemann U. Impairment of intracortical GABAergic inhibition in a rat model of absence epilepsy. Epilepsy Research 1995;22:43-51. [PubMed: 8565966]

[89]. Lytton, WW. From Computer to Brain. Springer Verlag; New York: 2002.

[90]. Lytton WW. Neural query system: data-mining from within the neuron simulator. Neuroinformatics 2006;4:163-176. [PubMed: 16845167]

[91]. Lytton WW, Destexhe A, Sejnowski TJ. Control of slow oscillations in the thalamocortical neuron: A computer model. Neuroscience 1996;70:673-684. [PubMed: 9045080]

[92]. Lytton WW, Hellman KM, Sutula TP. Computer network model of mossy fiber sprouting in dentate gyrus. Epilepsia - AES Proceedings 1996;37(S 5):117.

[93]. Lytton WW, Omurtag A. Tonic-clonic transitions in computer simulation. J. Clinical Neurophys 2007;24:175-181.

[94]. Lytton WW, Orman R, Stewart M. Computer simulation of epilepsy: implications for seizure spread and behavioral dysfunction. Epilepsy \& Behavior 2005;7:336-344. [PubMed: 16105749]

[95]. Lytton WW, Sejnowski TJ. Inhibitory interneurons may help synchronize oscillations in cortical pyramidal neurons. J Neurophysiol 1991;66:1059-1079. [PubMed: 1661324]

[96]. Lytton WW, Sejnowski TJ. Computer model of ethosuximide's e ect on a thalamic neuron. Ann Neurol 1992;32:131-139. [PubMed: 1510354]

[97]. Lytton WW, Stewart M. Rule-based firing for network simulations. Neurocomputing 2006;69:1160-1164.

[98]. Lytton, WW.; Stewart, M. Data-mining through simulation: introduction to the neural query system. In: Crasto, C., editor. Neuroinformatics. Humana Press; New York: 2007.

[99]. Markram H. The blue brain project. Nat Rev Neurosci 2006;7:153-160. [PubMed: 16429124]

[100]. Mathern GW, Babb TL, Mischel PS, Vinters HV, Pretorius JK, Leite JP, Peacock WJ. Childhood generalized and mesial temporal epilepsies demonstrate different amounts and patterns of hippocampal neuron loss and mossy fibre synaptic reorganization. Brain 1996;119:965-987. [PubMed: 8673505]

[101]. Mattia M, Del Giudice P. Efficient event-driven simulation of large networks of spiking neurons and dynamical synapses. Neural Computation 2000;12:2305-2329. [PubMed: 11032036] 
[102]. Meeren HK, Pijn JP, Van Luijtelaar EL, Coenen AML, Lopes da Silva FH. Cortical focus drives widespread corticothalamic networks during spontaneous absence seizures in rats. J Neurosci 2002;22:1480-1495. [PubMed: 11850474]

110. Seizures that appear to arise instantaneously are shown to have a distinct spatial course of spread.

[103]. Migliore M, Cannia C, Lytton WW, Hines ML. Parallel network simulations with neuron. J. Computational Neuroscience 2006;6:119-129.

[104]. Milton JG, Gotman J, Remillard GM, Andermann F. Timing of seizure recurrence in adult epileptic patients: a statistical analysis. Epilepsia 1987;28:471-478. [PubMed: 3653049]

[105]. Morgan RJ, Santhakumar V, Soltesz I. Modeling the dentate gyrus. Prog Brain Res 2007;163:639658. [PubMed: 17765743]

[106]. Morgan RJ, Soltesz I. Nonrandom connectivity of the epileptic dentate gyrus predicts a major role for neuronal hubs in seizures. Proc Nat Acad Sci USA 2008;105:6179-6184. [PubMed: 18375756]

115. A study showing how graph theory can make predictions that can be confirmed in an exploration of neuronal wiring.

[107]. Mulley JC, Scheffer IE, Petrou S, Berkovic SF. Channelopathies as a genetic cause of epilepsy. Curr Opin Neurol 2003;16:171-176. [PubMed: 12644745]

[108]. Ng A, Bursteinas B, Gao Q, Mollison E, Zvelebil M. Resources for integrative systems biology: from data through databases to networks and dynamic system models. Brief Bioinform 2006;7:318330. [PubMed: 17040977]

[109]. Nicholl JS. Cabbages and kings in the classification of seizures and the epilepsies. Epilepsia 2003;44:988. [PubMed: 12823587]

[110]. Noble D. Modeling the heart-from genes to cells to the whole organ. Science 2002;295:16781682. [PubMed: 11872832]

[111]. Noble D. The rise of computational biology. Nat Rev Mol Cell Biol 2002;3:459-463. [PubMed: 12042768]

[112]. Nunez, PL. Neocortical dynamics and human EEG rhythms. Oxford; NY: 1995.

[113]. Nunez, PL.; Srinivasan, R. Electric fields of the brain: the neurophysics of EEG. Vol. 2 edition. Oxford; NY: 2005.

[114]. Parent JM. Adult neurogenesis in the intact and epileptic dentate gyrus. Prog Brain Res 2007;163:529-540. [PubMed: 17765736]

[115]. Parent JM, Yu TW, Leibowitz RT, Geschwind DH, Sloviter RS, Lowenstein DH. Dentate granule cell neurogenesis is increased by seizures and contributes to aberrant network reorganization in the adult rat hippocampus. J Neurosci 1997;17:3727-3738. [PubMed: 9133393]

125. Cells are added during epileptogenesis.

[116]. Pedley, T.; Scharfman, HE. Temporal lobe epilepsy. In: Gilman, S., editor. Neurobiology of Disease. Academic Press; New York: 2006.

[117]. Pon, LS.; Sun, M.; Scheuer, ML.; Li, CC.; Sclabassi, RJ. Interictal spike analysis using stochastic point process; Fourth International Symposium on Uncertainty Modeling and Analysis; 2003; p. 262-267.

[118]. Prinz AA, Bucher D, Marder E. Similar network activity from disparate circuit parameters. Nat Neurosci 2004;7:1345-1352. [PubMed: 15558066]

[119]. Ratzliff AH, Howard AL, Santhakumar V, Osapay I, Soltesz I. Rapid deletion of mossy cells does not result in a hyperexcitable dentate gyrus: implications for epileptogenesis. J Neurosci 2004;24:2259-2269. [PubMed: 14999076]

[120]. Reggia, JA. A production rule system for neurological localization; Proceedings. The Second Annual Symposium on Computer Application in Medical Care; 1978; p. 254-260.

[121]. Robinson PA, Rennie CJ, Rowe DL. Dynamics of large-scale brain activity in normal arousal states and epileptic seizures. Phys. Rev. E Apr;2002 65(4):041924.

[122]. Rogawski MA. Diverse mechanisms of antiepileptic drugs in the development pipeline. Epilepsy Res 2006;69:273-294. [PubMed: 16621450]

[123]. Rogawski MA. Molecular targets versus models for new antiepileptic drug discovery. Epilepsy Res 2006;68:22-28. [PubMed: 16377151] 
[124]. Rogawski MA, Loscher W. The neurobiology of antiepileptic drugs for the treatment of nonepileptic conditions. Nature Medicine 2004;10:685-692.

[125]. Rudolph M, Destexhe A. Analytical integrate-and-fire neuron models with conductance-based dynamics for event-driven simulation strategies. Neural Comput 2006;18:2146-2210. [PubMed: 16846390]

[126]. Santhakumar V, Aradi I, Soltesz I. Role of mossy fiber sprouting and mossy cell loss in hyperexcitability: a network model of the dentate gyrus incorporating cell types and axonal topography. J Neurophysiol 2005;93:437-453. [PubMed: 15342722]

[127]. Scharfman HE. The neurobiology of epilepsy. Curr Neurol Neurosci Rep 2007;7:348-354. [PubMed: 17618543]

[128]. Scharfman, HE.; Schwarcz, R. Neuromodulation of seizures, epileptogenesis, and epilepsy. In: Engel, J.; Pedley, TA.; Aicardi, J.; Dichter, MA.; Moshe, S., editors. Epilepsy: A Comprehensive Textbook. Vol. 2 edition. Lippincott; New York: 2007.

[129]. Schramm J, Aliashkevich AF, Grunwald T. Multiple subpial transections: outcome and complications in 20 patients who did not undergo resection. J Neurosurg 2002;97:39-47. [PubMed: 12134931]

[130]. Sejnowski TJ, Koch C, Churchland PS. Computational neuroscience. Science 1988;241:1299_ 1306. [PubMed: 3045969]

[131]. Sloviter RS. The functional organization of the hippocampal dentate gyrus and its relevance to the pathogenesis of temporal lobe epilepsy. Annals of Neurology 1994;35:640-654. [PubMed: 8210220]

[132]. Soltesz, I.; Staley, K. Computational Neuroscience in Epilepsy. Academic Press; San Diego: 2008. 143. An excellent compendium of recent results.

[133]. Song J, Tanouye MA. From bench to drug: human seizure modeling using drosophila. Prog Neurobiol 2008;84:182-191. [PubMed: 18063465]

[134]. Spampanato J, Aradi I, Soltesz I, Goldin AL. Increased neuronal firing in computer simulations of sodium channel mutations that cause generalized epilepsy with febrile seizures plus. $\mathbf{J}$ Neurophysiol 2004;91:2040-2050. [PubMed: 14702334]

[135]. Stafstrom CE. Epilepsy: a review of selected clinical syndromes and advances in basic science. J Cereb Blood Flow Metab 2006;26:983-1004. [PubMed: 16437061]

[136]. Strogatz SH. From Kuramoto to Crawford: exploring the onset of synchronization in populations of coupled oscillators. Physica D: Nonlinear Phenomena 2000;143:1-20.

[137]. Strogatz SH. Exploring complex networks. Nature 2001;410:268-276. [PubMed: 11258382]

[138]. Suffczynski P, Kalitzin S, Lopes da Silva FH. Dynamics of non-convulsive epileptic phenomena modeled by a bistable neuronal network. Neuroscience 2004;126:467-484. [PubMed: 15207365]

[139]. Suffczynski P, Lopes da Silva FH, Parra J, Velis DN, Bouwman BM, van, Rijn CM, van, Hese P, Boon P, Khosravani H, Derchansky M, Carlen P, Kalitzin S. Dynamics of epileptic phenomena determined from statistics of ictal transitions. IEEE Trans Biomed Eng 2006;53:524-532. [PubMed: 16532779]

[140]. Sunderam S, Osorio I, Frei A, Watkins JF. Stochastic modeling and prediction of experimental seizures in sprague-dawley rats. J Clin Neurophysiol 2001;18:275-282. [PubMed: 11528299]

[141]. Sutula T, Cascino G, Cavazos J, Parada I, Ramirez L. Mossy fiber synaptic reorganization in the epileptic human temporal lobe. Ann Neurol 1989;26:321-330. [PubMed: 2508534]

[142]. Traub RD, Contreras D, Cunningham MO, Murray H, LeBeau FE, Roopun A, Bibbig A, Wilent WB, Higley MJ, Whittington MA. Single-column thalamocortical network model exhibiting gamma oscillations, sleep spindles, and epileptogenic bursts. J Neurophysiol 2005;93:2194-2232. [PubMed: 15525801]

154. A detailed model of the operation of a single column with applications in epilepsy and normal activity.

[143]. Traub RD, Contreras D, Whittington MA. Combined experimental/simulation studies of cellular and network mechanisms of epileptogenesis in vitro and in vivo. J Clin Neurophysiol 2005;22:330 342. [PubMed: 16357637] 
[144]. Traub, RD.; Jefferys, JGR.; Whittington, MA. Fast Oscillations in Cortical Circuits. MIT Press; Cambridge, MA: 1999.

[145]. Traub RD, Miles R, Wong RKS. Model of the origin of rhythmic population oscillations in the hippocampal slice. Science 1989;243:1319-1325. [PubMed: 2646715]

[146]. Tsakalis, K.; Chakravarthy, N.; Iasemidis, L. Control of epileptic seizures: Models of chaotic oscillator networks; 44th IEEE Conference on Decision and Control; 2005; p. 2975-2981.

[147]. TY LYL, Yorke JA. Period three implies chaos. Amer. Math. Monthly 1975;82:985-992.

[148]. Ullah M, Wolkenhauer O. Family tree of Markov models in systems biology. IET Syst. Biol 2007;1:247-254. [PubMed: 17708432]

[149]. van Drongelen W, Lee HC, Hereld M, Chen Z, Elsen FP, Stevens RL. Emergent epileptiform activity in neural networks with weak excitatory synapses. IEEE Trans Neural Syst Rehabil Eng 2005;13:236-241. [PubMed: 16003905]

[150]. van Drongelen W, Lee HC, Stevens RL, Hereld M. Propagation of seizure-like activity in a model of neocortex. J Clin Neurophysiol 2007;24:182-188. [PubMed: 17414974]

[151]. Vendrame M, Khurana DS, Cruz M, Melvin J, Valencia I, Legido A, Kothare SV. Aggravation of seizures and/or EEG features in children treated with oxcarbazepine monotherapy. Epilepsia 2007;48:2116-2120. [PubMed: 17645535]

[152]. Watts DJ, Strogatz SH. Collective dynamics of 'small-world' networks. Nature 1998;393:440442. [PubMed: 9623998]

[153]. Watts, L. Event-driven simulation of networks of spiking neurons. In: Cowan, JD.; Tesauro, G.; Alspector, J., editors. Advances in neural information processing systems. Vol. 6. Morgan Kaufmann Publishers; 1994. p. 927-934.

[154]. Wendling F. Neurocomputational models in the study of epileptic phenomena. J Clin Neurophysiol 2005;22:285-287. [PubMed: 16357633]

[155]. Wendling F, Bartolomei F, Bellanger JJ, Chauvel P. Epileptic fast activity can be explained by a model of impaired GABAergic dendritic inhibition. Eur J Neurosci 2002;15:1499-1508. [PubMed: 12028360]

168. Application of a lumped model to MTLE.

[156]. Wieser HG. ILAE commission report. Epilepsia 2004;45:695-714. [PubMed: 15144438]

[157]. Williams TL. Phase coupling by synaptic spread in chains of coupled neuronal oscillators. Science 1992;258:662-665. [PubMed: 1411575]

[158]. Wilson HR, Cowan JD. Excitatory and inhibitory interactions in localized populations of model neurons. Biophysical Journal 1972;12:1-24. [PubMed: 4332108]

[159]. Wilson MT, Sleigh JW, Steyn-Ross DA, Steyn-Ross ML. General anesthetic-induced seizures can be explained by a mean-field model of cortical dynamics. Anesthesiology 2006;104:588-593. [PubMed: 16508406]

[160]. Winfree AT. Biological rhythms and the behavior of populations of coupled oscillators. J Theor Biol 1967;16(1):15-42. [PubMed: 6035757]

[161]. Wolfram S. Computer software in science and mathematics. Scientific American 1984;251:188204.

[162]. Wong S, Gardner AB, Krieger AM, Litt B. A stochastic framework for evaluating seizure prediction algorithms using hidden Markov models. J Neurophysiol 2007;97:2525-2532. [PubMed: 17021032]

176. A Markov model applied to the underlying states to be predicted by a seizure prediction algorithm.

[163]. Yu AC. Methods in biomedical ontology. Journal of Biomedical Informatics 2006;39:252-266. [PubMed: 16387553] 


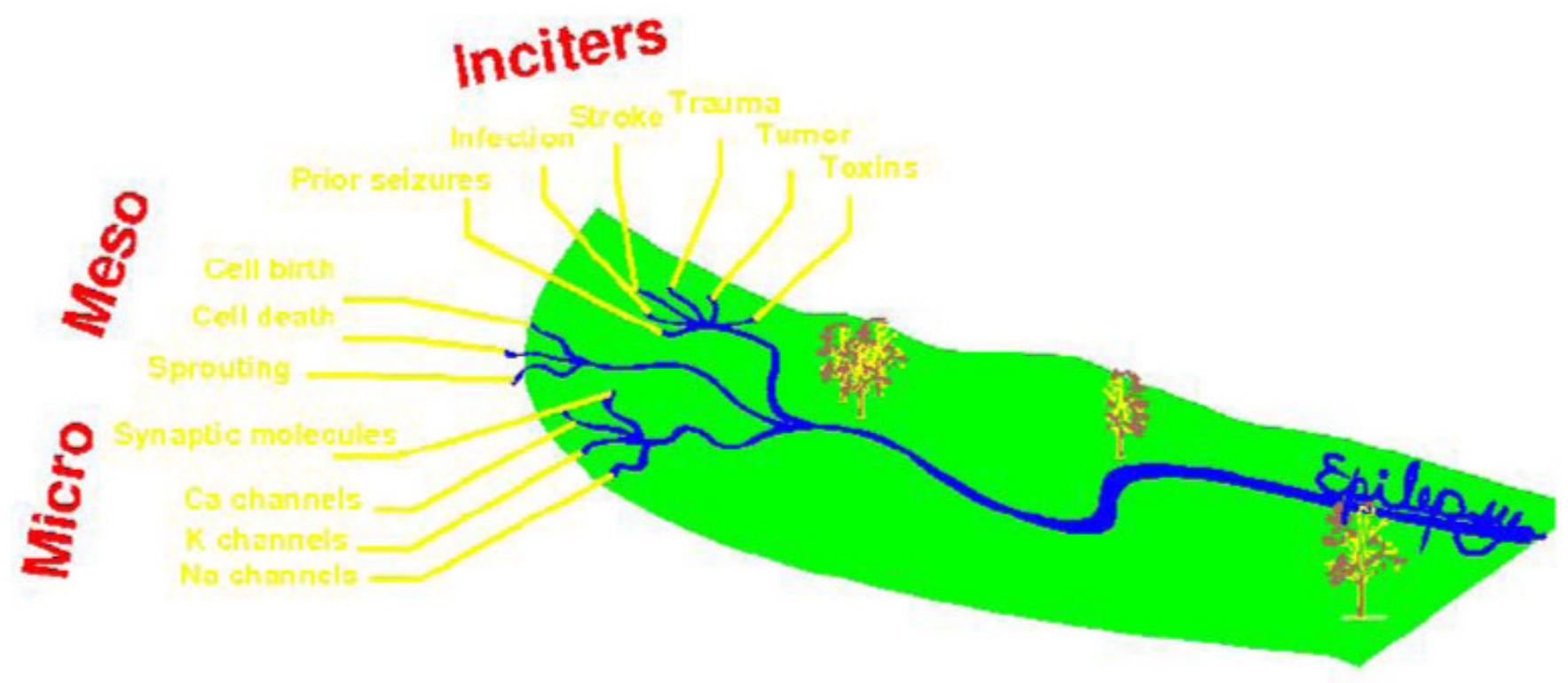

Fig. 1.

The river of epilepsy. Multiple genetic factors and various acquired insults, here represented as tributaries, feed into epilepsy causation. Factors have been grossly divided into micro-, meso- and macro- levels of change or insult. Many genetic and epigenetic factors come into play in producing combinations of voltage-channels and ligand-sensitive that may contribute to an epileptic state. Sodium, potassium and calcium channels as well as both excitatory and inhibitory synaptic receptors are implicated. Combinations of channel alleles may cause epilepsy in situations where one allele alone would not or, remarkably, reduce the epilepsy that would be caused by either one alone. ${ }^{56}$ In addition to these factors, life events such as head trauma can incite cell death or wiring changes that will contribute to a greater or lesser extent when combined with the genetic factors. Similarly, toxins or drugs can contribute to the epileptic state. This complex, multifactorial causality generally precludes the identification of the root cause of epilepsy in an individual patient or in a class of patients. Instead we must think in terms of complex systems, using tools that enable us to manipulate and understand complex systems. Modified from Lennox and Lennox. ${ }^{81}$ 


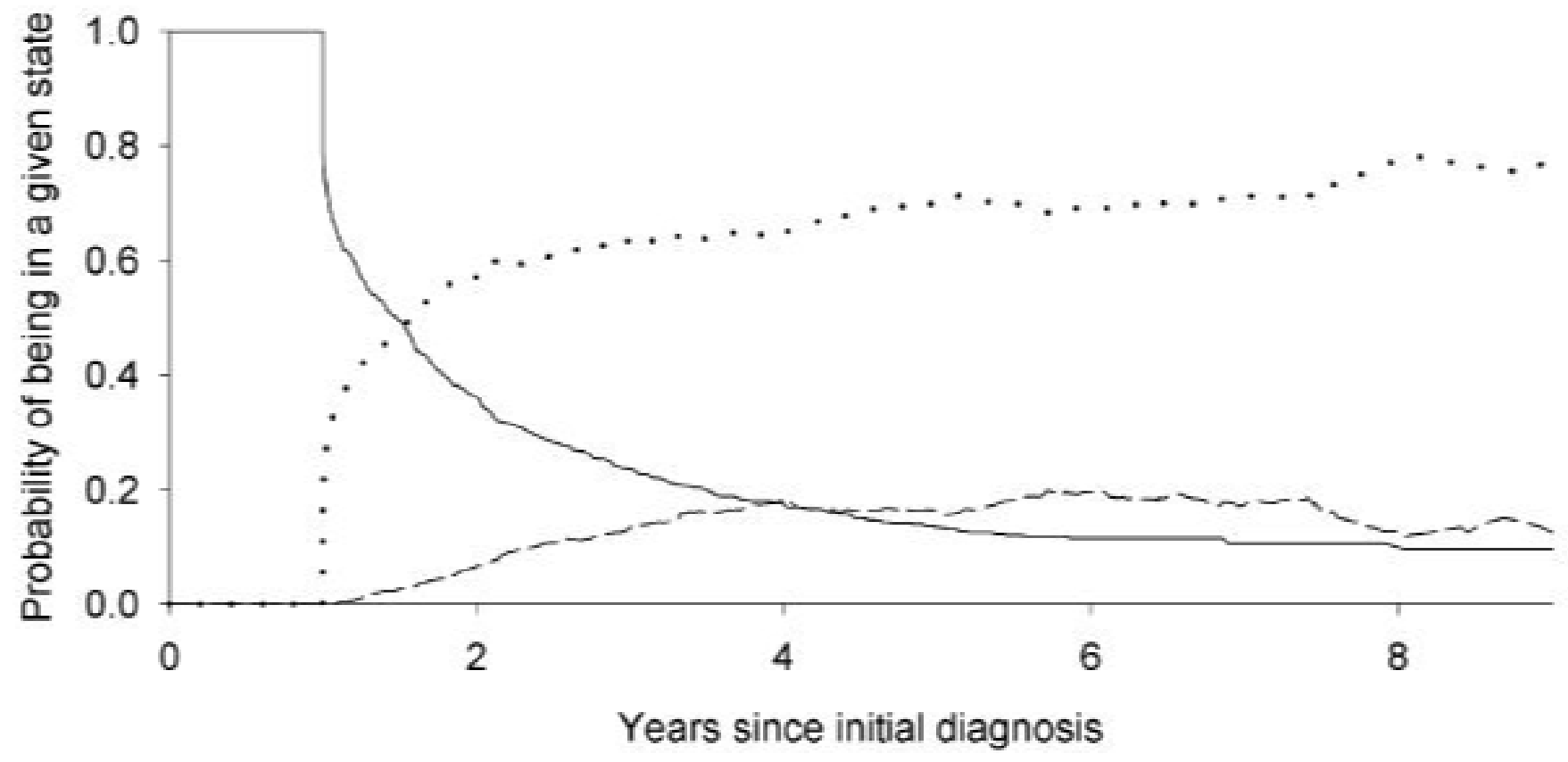

\section{- State 1, never in remission \\ ... State 2, in remission \\ -- State 3 , no longer in remission}

Fig. 2.

Markov model of childhood epilepsy outcome in 602 children. The model consists of 3 states: initial disease (State 1, a starting state to which there is no return), remission (State 2) and relapse (State 3). A time constant of 1 year seizure-free was used to define remission. The model indicated that the probability for being in each of the 3 states plateaued over a 5-year period. The majority of patients go into remission (stop having seizures) though some of these will relapse. Note that these results could not have been readily obtained using standard statistical measures. This is partially due to the nature of the sample: patients are enrolled over time so only a few if any are followed for the full 8 years of the study - there is no single time point where all patients can be assessed. This is also due to the difficulty of extrapolating probabilities out across multiple cycles of remission and relapse. (From Berg et al. 2004, Fig $1^{7}$ ) 

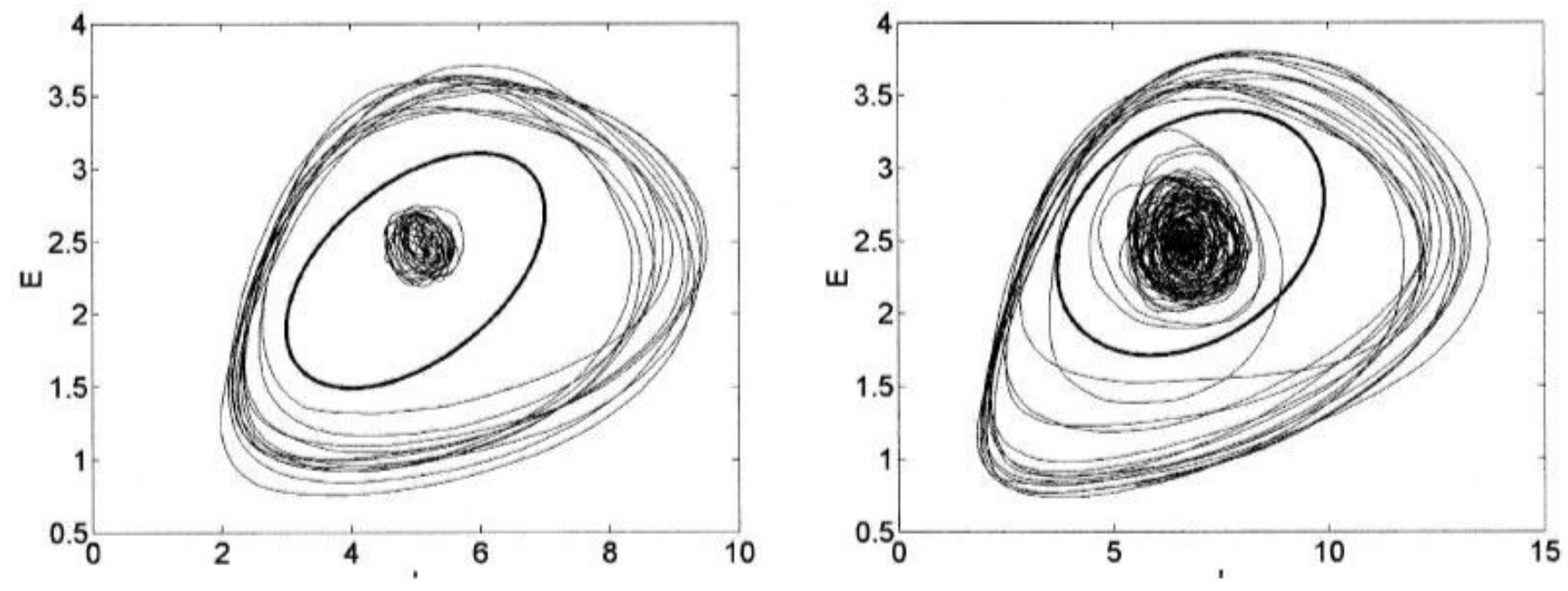

Fig. 3.

A lumped model of absence epilepsy. Sample trajectories (thin lines) from normal (left) and epileptic model (right) projected onto a 2-dimensional slice of state space. The axes are values of two state variables: cortical excitatory and inhibitory activity. The red line is a separatrix separating 2 attractors. The attractors are not explicitly represented but can be inferred from the trajectories. In both cases normal activity is the inner trajectory and a seizure is the outer trajectory (higher amplitude activity). Note that the seizure attractor exists even for the normal model - corresponding to the fact that anyone can have a seizure under stress conditions: such as fever, ischemia, hypoglycemia or insomnia. However the attractors are well separated in the normal model so that random perturbations do not result in transitions. In the epileptic model, the attractors are closer and perturbations produce transitions to seizure. (From Lopes da Silva et al. 2003, Fig. 2 85) 


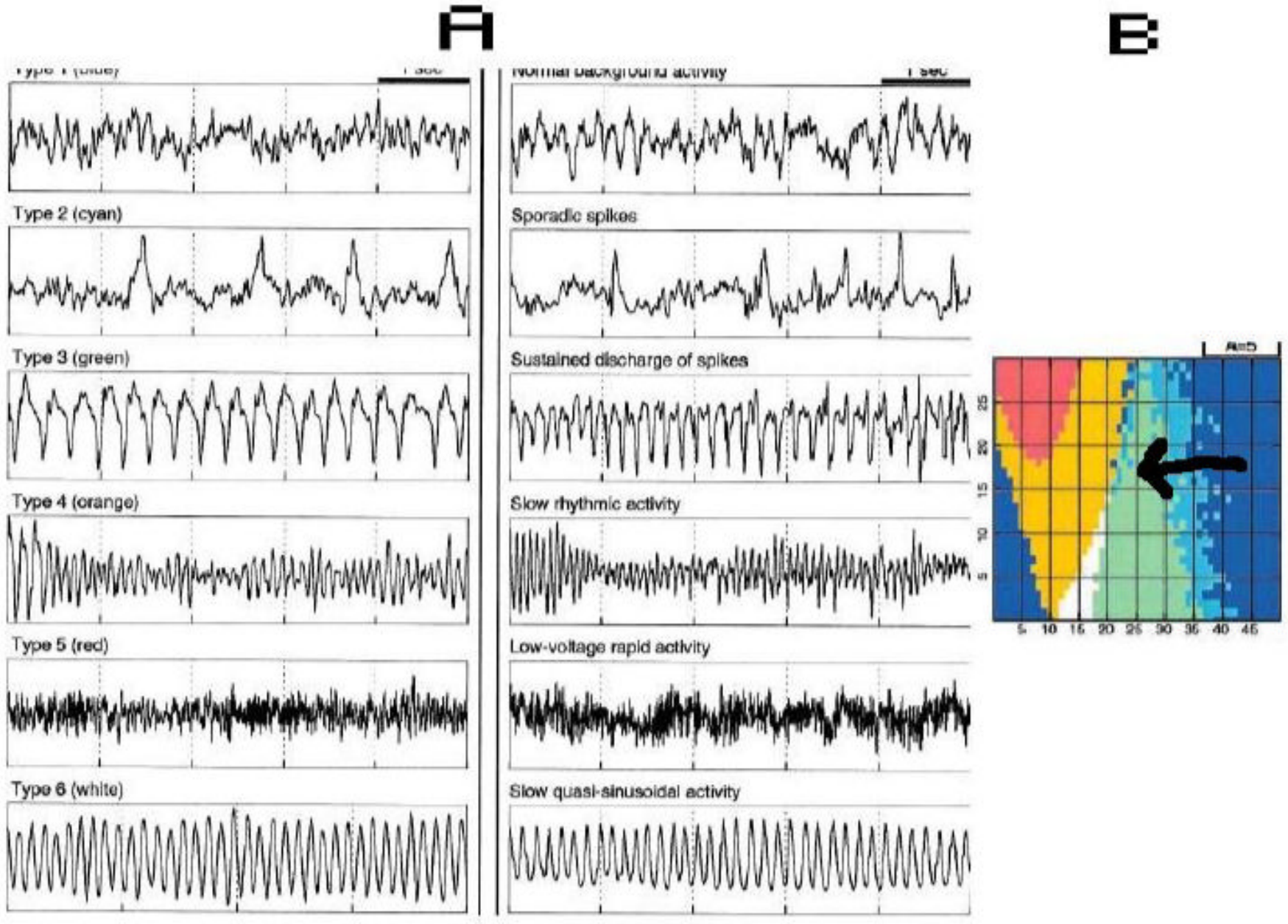

Fig. 4.

A lumped model of MTLE. A. Simulated cortical EEG from a lumped model of excitatory and inhibitory interactions produced a variety of activity patterns (left) comparable to those seen in depth recordings from human patients (right). Each of the color-coded patterns is a result of a different location in a two-dimensional slice of parameter space (B). In the simulated traces, we are only seeing a single state-variable (the excitatory activity) comparable to the y-axis of the two-dimensional portrait in Fig. 3. Note that this single state-variable is only the dimensional tip of the ten-dimensional state space used in this model: most of the interactions and transitions are hidden from view. B: Parameter space. The slow inhibitory parameter is shown on the $\mathrm{y}$-axis and the fast inhibitory parameter on the $\mathrm{x}$-axis. One route from normal activity to a seizure is shown by the arrow: downward movement in parameter space from the topmost blue area (normal activity) to the green area (seizure). This movement represents a decrease in the parameter for slow (largely dendritic) inhibition. Hence the model makes a specific prediction that a reduction in these inhibitory inputs could be responsible for transitions to the seizure. (Adapted from Wendling et al. 2002, Figs. $3,4^{155}$ ) 

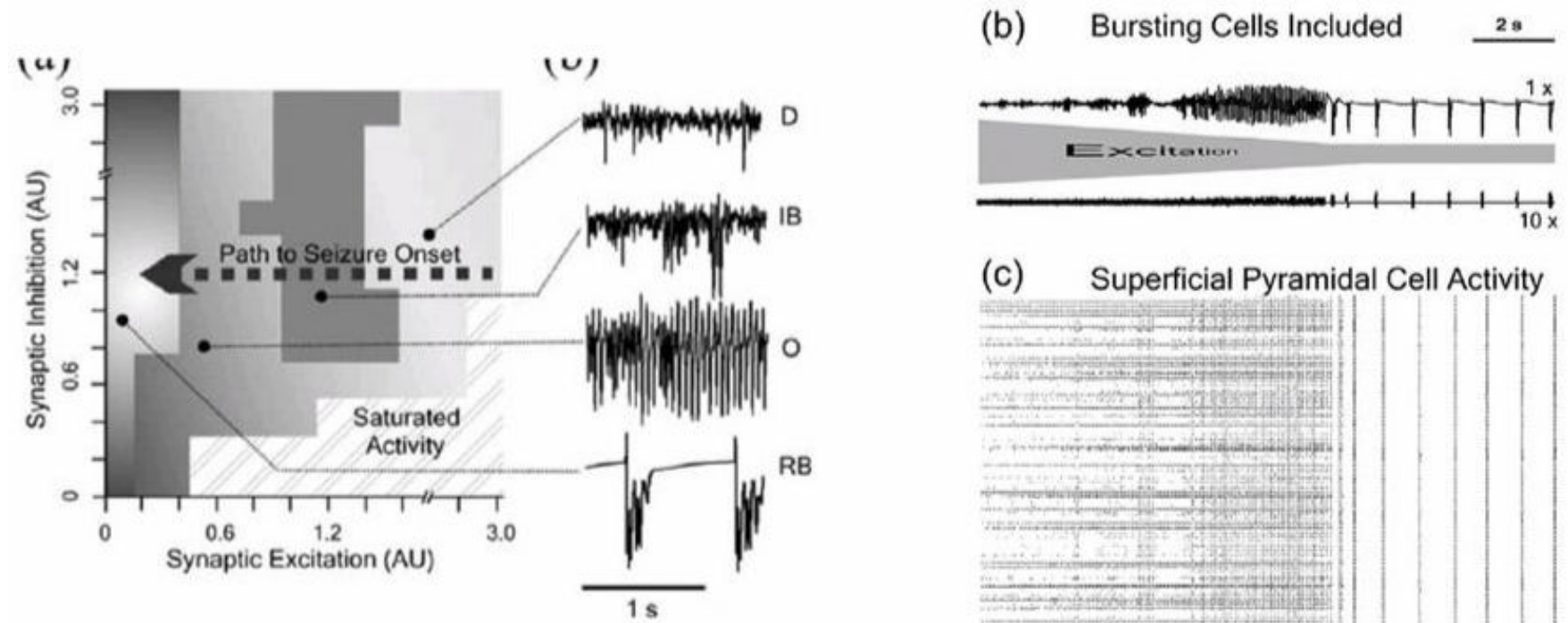

Fig. 5.

Reduction of excitatory strength leads to seizure in a detailed neocortical model. Unlike in the lumped models above, individual neurons are here represented by compartmental models sections of dendrite and the soma are represented as separate resistor-capacitor circuits in parallel with active channels represented by Hodgkin-Huxley channel models (the parallel conductance model). These individual compartments are then linked together with resistors that represent the axial resistance. The single neuron is simulated by performing numerical integration of the associated differential equations. Synaptic dynamics are also represented by differential equations. The model has 656 neurons representing 4 types (regular-firing pyramidal, bursting pyramidal, basket cell, chandelier cell) A. Movement in parameter space from high to low excitation (right to left) leads from normal activity (top trace) to high amplitude seizure-like bursting (bottom trace). Note that this result is different from that in Fig. 4. B. Gradual development of bursting is seen as excitatory connectivity strength is gradually reduced. Top trace shows field generated by excitatory and bottom field generated by inhibitory cells. C. Raster plot of firing for individual superficial pyramidal cells in the network.(Adapted from van Drongelen et al. 2005, Figs. 2, $3^{149}$ ) 